\title{
Community Informatics and Sustainability: Why Social Capital Matters
}

\author{
Lyn Simpson \\ Queensland University of Technology $<$ le.simpson@qut.edu.au $>$
}

\begin{abstract}
This paper adopts a holistic approach to explain why social capital matters for effective implementation, widespread uptake, greater social inclusion, and the sustainability of CI initiatives. It describes a theoretical framework drawn from diffusion of innovation, community development and social capital theories. The framework emphasises the interplay between physical infrastructure (including hard technologies and their location in the community), soft technologies (including capacity building, education, training and awareness raising), social infrastructure (including local networks and community organisations) and social capital (including trust and reciprocity, strong sense of community, shared vision, and outcomes from participation in local and external networks).
\end{abstract}

\section{Introduction}

The economic and social viability of rural communities has been an ongoing concern, with highly uneven levels of growth and decline in non-metropolitan Australia (Haberkorn et al., 1999). At the same time, governments at federal, state and local levels are steadily adopting ICTs for the delivery of services, providing communities with more integrated and responsive services (Queensland Department of Communication, Information, Local Government and Planning, 1999). Government see ICTs as critical for maximising economic opportunities, ensuring international competitiveness and "build[ing] a better, more prosperous and fairer Australia" (Innovate Australia, 1995). Government policy also acknowledges that Internet connectivity and skill are key factors in ensuring that individuals can fully share in the social and economic benefits offered by ICT (National Office for the Information Economy, 2000).

However, in rural Australia, distance from metropolitan centres has had a negative impact on service delivery to many communities, but particularly on ICT-based services because of the high cost per capita of providing and servicing ICTs. This can mean that those in more remote locations with the most critical needs are more likely to have limited and costly telecommunications services (US Congress, Office of Technology Assessment, 1991). Since access to ICT is seen to be increasingly essential for full participation in contemporary society, rural communities that have only minimal or costly access to ICTs have limited opportunities to explore the social and economic advantages that new technologies can offer (Bikson \& Panis, 1995).

The 'digital divide' is a term frequently used to describe the social implications of unequal access to ICTs and the resulting limited development of ICT related skills for some sectors of the community (National Office for the Information Economy, 2000; Simpson et al., 2001; Wilding 2001). Recently, using the 'digital divide' to contrast those that have access with those that do not has been challenged. A binary digital divide has been criticised for its technological determinism and overemphasis on access to technology as the single overriding factor that determines or closes the divide for marginalised groups, likened to "applying technology as an educational Band-Aid" (Warschauer, 2003, p.47). Such a view 
denies the myriad ways that technology is accessed, usually woven into social systems and processes as part of social networks involving relatives, friends and colleagues. Similarly, Grunwald (1997) notes that technology initiatives alone are not a panacea unless they are embedded in processes of community development, where the emphasis is not on the technology and what it can do, but on how the technology can be used strategically to meet community needs. The intent of policy then should extend beyond solving the 'divide' through mere access to technology, but instead focus on strategies that foster social inclusion, mobilise community support for achieving community goals, and thereby 'multiply' the existing community assets (Warschauer, 2003, p.47). The concept of social capital is a useful lens through which to examine the elements of sustainable initiatives.

Social capital is used to describe beneficial outcomes that can be derived from 'multiplying' existing community assets, such as trust, reciprocity and cooperation, shared values and norms, pro-activity and leadership, and a strong sense of community that can result from interaction and participation in strong social networks in a community (see Putnam, 1993; Fukuyama, 1995; Onyx \& Bullen, 2000; Woolcock, 2001). High levels of social capital are usually indicated by community members who feel a strong sense of belonging, a willingness to participate in community activities, and a commitment to actively work towards the future well-being of their community. In such communities, social inclusion and participation by diverse community members are valued because of the increased potential and opportunities for building community social capital. When lack of access to ICTs or limited ICT skills prevents effective participation by individuals in social, economic or civic activities in their local community or society generally, then opportunities for building community social capital are substantially reduced.

Furthermore, social capital and recognition of the centrality of community are central to the sustainability of both communities and of their CI initiatives (Cernea, 1993). The World Bank (1998) highlighted the growing body of evidence that the size and density of social networks and institutions and the nature of interpersonal interactions are significant determinants of the sustainability of development initiatives.

Community informatics (CI) brings together community development and the opportunities afforded by community ICT-based initiatives (Gurstein, 1999) such as community technology centres, community access programs, Internet or cybercafes, electronic commerce, community and civic networks and online participation. CI initiatives provide innovative ways and increased opportunities for community members to interact both locally and globally, often stimulating a greater range of economic, social and civic activities. CI research provides insights into how CI projects can be better implemented by considering the contextual and social factors that affect CI developments and use (O'Neil, 2002), and by identifying and understanding barriers to technological diffusion in communities (Kling, 2000). In this way, the impact of sustainable CI initiatives, providing ongoing opportunities for access to ICTs and participation in community activities can extend, well beyond enabling access to ICTs, to strengthening social networks and increasing community social capital.

In Australia and internationally, there have been many successful reports of CI initiatives, such as the introduction of community technology centres, telecottages and telecentres (see for example Albrechtsen, 1998; Horner \& Reeve, 1991; Hunter, 1999; O’Neil, 2002). At the same time, others have raised concerns about the impact of $\mathrm{CI}$ initiatives on communities, and the conditions that affect the implementation of such initiatives (Easdown, 1997; Dabinett, 2000). Reasons for the lack of success of a number of CI projects in the UK included the tension between commercial and community aspects of the network, poor communications, unrealistic expectations, conflicting agendas, a continual need for capital and inadequate strategic and operational management (Dabinett, 2000). Other communities have found that "government interventions that neglect or undermine [the] social infrastructure can go seriously awry," and that such well-intentioned projects can "heedlessly ravage existing social networks" (Putnam, 1993, p. 4), both by creating new pressures on previously sound community networks and by being a catalyst for exacerbating 'cracks' that may already exist in a community.

This paper expands a CI perspective to analyse a number of a number of collaborative CI research projects in rural and remote communities in Queensland, Australia (Simpson et al., 2001; Rural Women and ICTs Research Team, 1999; Simpson, 1998). The projects investigated the ways that CI initiatives can be effectively implemented to address individual and community objectives; can facilitate rural community development; and can facilitate networks within the local community and more broadly, such as with 
government, industry and other global communities. Project findings emphasised the importance of sustainability as a key element of CI initiatives if they are to build ICT skills and capacity, encourage widespread uptake of ICTs, achieve greater social inclusion, build social capital and enable communities to fully capitalise on the potential of ICTs for community development. While drawing on these projects, the focus of this paper is not to detail these outcomes, but instead to describe a theoretical framework that emphasises the importance of adopting a more holistic approach to understanding the complex social factors that can affect the uptake, outcomes and sustainability of CI initiatives.

The framework discussed below brings together aspects of three key theories that can assist in unravelling the complexity inherent in community informatics initiatives. Firstly, diffusion of innovation theory increases awareness of the ways and rate at which new ideas are disseminated and individual community members take up ICT innovations. Secondly, community development and capacity building analyses provide an increased understanding of processes that underpin community developments such as CI initiatives, and the importance of a sense of community ownership and building local capacity to addressing community issues. Finally, discussions of social capital present the intangible but valuable social features of community life that are the outcomes of strong social networks and community interaction, and that influence community attitudes to change and future well-being.

Thus, the framework encompasses theories that elaborate the interplay in $\mathrm{CI}$ initiatives between the physical infrastructure (including hard technologies and their location in the community), soft technologies (focusing on building capacity such as awareness raising, education, training and leadership), social infrastructure (including local networks, resources, services, and community organisations) and social capital (including trust and reciprocity, strong sense of community, shared vision, and outcomes from participation and interaction in local and external networks).

In the following section the paper describes aspects of the three theories: diffusion of innovation, community development and capacity building, and social capital that provide a foundation for effective implementation of CI initiatives, and goes on to discuss why these three theories matter to CI sustainability.

\section{Diffusion of innovations}

Diffusion of innovation research has a long tradition across a range of disciplines (Kautz \& Larsen, 2000; Rogers, 1995; Tornatsky \& Fleischer, 1990). Diffusion of innovation literature describes patterns of technology adoption, explains the process of a particular technology's use within a social system, and assists in predicting whether and how a new innovation will be successful (Kautz, 1999). In this way, diffusion of innovation theory can inform effective planning and implementation of CI initiatives by increasing our understanding of the ways and rates at which rural and remote community members take up ICT innovations.

There are four generally accepted elements which describe the diffusion of innovation process: the innovation itself; the communication channel(s) through which it is disseminated; the timeframe in which this occurs; and the social system where the innovation is introduced (Charlton et al., 1998).

Rogers' (1995) diffusion of innovation paradigm has been particularly influential in elaborating these elements. It describes the characteristics of an innovation that influence the rate of adoption. It also requires that a diffusion process considers the norms and beliefs of a social system and examines adopter behaviour and rates of adoption by individuals within their local contexts. Further, it highlights the influential role of opinion leaders and change agents in diffusing innovation in a community through their social networks, corresponding with other rural research that emphasizes the importance of 'champions' in creating change in rural communities (Sher \& Sher, 1994; Goodman, 1998; Falk, 1999; Korsching et al., 2000).

\section{Networks}

Diffusion theory also emphasizes a communication process that is more complex than the simple persuasion of a community member to explore a new idea or technology. Effective diffusion involves much more than dissemination at an individual community member level; it is a reciprocal process that also relies on the implementation of strategies through various settings and systems, using a variety of formal and informal media and communication channels (Oldenburg \& Hardcastle, 1997). Particularly relevant here is 
the role of networks in diffusing a new idea or technology within a social system (Valente \& Davis, 1999), such as a community. Diffusion theory accentuates the value of social networks or interpersonal channels over and above mass media for innovation adoption decisions, highlighting the role of opinion leaders and change agents in mediating the impact of mass media communications, because most people evaluate a new idea based on the subjective evaluation of someone like themselves who has previously adopted the idea (Rogers, 1995).

For CI initiatives, engaging diverse groups of community members and a broad range of community organizations assists the diffusion process across different sectors of the community. Identifying and building the ICT skills of influential members of those diverse groups and organizations will exploit the potential for local opinion leaders to tailor their persuasion to those aspects of the innovation that accord with the values, norms and beliefs of their immediate networks, and, in turn, influence others' attitudes towards using the Internet across different sectors of the community. Thus, potential adopters become active participants in the adoption and diffusion process, giving their own unique meaning to the innovation as it is applied in their local context. In this way, adoption and diffusion of CI initiatives are fundamentally social processes dependent on interpersonal networks, and the values, norms and beliefs of the local community.

\section{Innovation attributes}

A further important aspect of diffusion of innovation theory is the way the innovation itself is perceived by potential adopters, and how rates and patterns of diffusion are influenced by perceptions of the innovation's attributes (Kautz \& Larsen, 2000). More specifically, perceptions of an innovation are shaped by the degree to which an innovation is perceived to be better than the way things are currently done (relative advantage); consistent with existing, values, beliefs, experience and needs (compatibility); user friendly rather than difficult to understand or use (complexity); easily trialled (trialability); and readily observed, with visible outcomes (observability) (Rogers, 1995).

These characteristics provide a useful basis for understanding where and how a CI initiative can be implemented in a community to best influence community members' perceptions of the innovation and to maximize widespread diffusion.

\section{Locating the innovation}

Drawing on diffusion theory, a CI initiative such as Internet access, is ideally established in a location where community members have the opportunity to:

- Understand the potential for online access to better meet their needs for access to information and services (relative advantage) through demonstrations of the technology, local media, and through participating in diverse local networks to hear a range of user experiences with the technology.

- Feel comfortable accessing the Internet because use of the Internet matches their own and their community's norms, values and aspirations (compatibility) and they are able to have access in a non-threatening environment that encourages sharing of their Internet experiences with other similar users.

- See how easily they can learn and adapt to using the Internet (complexity) by providing training and training materials in jargon-free language, targeted to specific user needs and levels of experience with using the Internet.

- Experiment with using the Internet (trialability) to see what information or services it can provide, particularly if they have free access, workshops and information sessions to encourage participation.

- Better understand what can be achieved through Internet access by watching other community members using it (observability) and by using Internet access point where it will be seen by a wide range of community members.

Thus, for CI initiatives, diffusion of innovation research suggests that where and how community members engage with the CI should be tailored to meet individual user needs. This includes both the environment - in terms of atmosphere, décor, and staff - and the experience - in terms of diverse locations 
for Internet access, different approaches to training, and varying the levels and types of information provided. Users need a non-threatening, supportive environment in which to observe, explore, and experiment with the technology, and to gain an understanding of its use and relevance to their daily lives. More skilled and confident individuals seeking advanced information about the Internet will have different needs from those without confidence and with limited skills. Novice users are likely to benefit from a supportive, comfortable setting and a less formal, more social introduction to the innovation, aimed at building their confidence to explore the Internet.

When CI initiatives do not have funding for multiple access sites, catering for diverse user needs can be achieved by allocating specific times for different groups to use the Internet access. For example, in one community with only one access site, a Thursday morning is set aside for groups of older members of the community to use the CI facility, while Saturday nights are allocated to youth in the community (Simpson, 1998).

\section{Time}

A further element of diffusion theory is time. Having any new idea adopted takes time, even for those ideas that appear to have obvious benefits, and it can take many years before the innovation is widely adopted. Most innovations diffuse slowly and require a critical mass of at least $10-25 \%$ of potential adopters to trigger uptake through their interpersonal networks and for the rate of diffusion to accelerate (Rogers, 1995). For example, it took 30 years for the telephone to achieve its role in personal communications (Fischer, 1994).

The average time between potential adopters becoming aware of an innovation and taking the decision to adopt can vary widely and is influenced by adoption behaviour. Potential adopters of an innovation can be divided into several adopter types that indicate the likelihood of their adopting the innovation: innovators $(2.5 \%)$, early adopters $(13.5 \%)$, early majority $(34 \%)$, late majority $(34 \%)$ and those reluctant to adopt referred to as laggards (16\%) (Rogers, 1995). One study showed that the difference between the innovators and the laggards adopting was 4.25 years - innovators adopted after .4 years, early adopters .55 years, early majority 1.14 years, late majority 2.34 years, and laggards 4.65 years (Rogers, 1995, p.201).

Patterns and rates of adoption behaviour, and the time needed for widespread diffusion, have important implications for CI initiatives. Sustained CI initiatives with ongoing access to ICTs are critical for disseminating widespread knowledge of the technology and building user confidence. Sustainability is also important for the community to shape the innovation to meet its own needs. Links between diffusion of the innovation and social change are rarely immediately obvious, but only emerge as widespread adoption occurs and community members shape further development (Kiesler, 1986; Gillard, Wale \& Bow, 1996), and users translate and adapt the technology to their own requirements by shaping its uses and meanings (Hellman, 1996). Consequently, where communities have only short term funding for CI initiatives, diffusion of the Internet will be restricted to a relatively limited group of innovators and early adopters, minimizing the potential for community economic and social change, and inventive uses of the technology.

\section{Learnings from diffusion of innovation}

In terms of CI initiatives, diffusion of innovation highlights the importance of:

- Being able to access and experiment with the technology, to observe others using it, to learn how to use the technology in a user-friendly way, and to examine its potential and relevance to the norms and values of the individual user and the local community.

- Providing appropriate access to the technology in social settings that cater for different groups in the community. Diffusion research emphasises the need to vary the setting and approaches to meet diverse users' needs.

- Recognizing the role of local opinion leaders and change agents who can influence other community members' attitudes towards using the innovation. Diffusion research has demonstrated that most people depend on subjective evaluations of an innovation by people like themselves who have already experimented with and/or adopted the idea.

- Accentuating the value of local social networks by raising awareness of the diverse groups and organizations already existing in the community, by encouraging the participation of individuals 
from different groups and organizations and other key individuals in the community, and by creating opportunities for emergent leadership.

- Understanding that diffusion of any innovation takes time and that sustainability of CI initiatives is essential for widespread adoption across the broader community, beyond the innovators and early adopters. Short term project funding as the basis for a CI initiative limits potential outcomes, not only in terms of ICT access but in overall impact on the community.

The integral relationship between diffusion of an innovation and the social setting of the local context in which it is introduced is often overlooked by policy advisers who sometimes adopt an 'individual blame bias' (Rogers, 1995). In rural communities, such a bias apportions blame to the community for not taking full advantage of CI initiatives or ensuring their sustainability. It does not realistically account for other issues such as inadequacy of telecommunications infrastructure, lack of access to ICTs, lack of availability to appropriate training, and inadequate financial resources to address such issues and build the human capacity and social infrastructure critical to sustaining $\mathrm{CI}$ initiatives.

The paper now turns to community development and capacity building literature to examine how community development processes can influence the sustainability of a CI initiative, and how such processes accord with diffusion theory.

\section{Community Development and Capacity Building}

'Community' has been used in many contexts and defined in many ways (see for example Hillery, 1955 and Bell \& Newby, 1971 in Smith, 1996). In many uses and definitions, geographical territory, common ties or goals, and social interaction are key elements (Smith, 1996). Others highlight the importance of virtual community (Rheingold, 1995), belonging, connection and shared responsibility (Milio, 1996), and the linkages and interrelationships that identify individuals as part of a community (Lane \& Dorfman, 1997). In terms of understanding CI initiatives in geographical communities, this paper argues for community to be regarded from an interactional perspective. Thus, community interrelationships and community interaction are considered key defining elements of community as people work together to solve problems and improve the well-being of the local community they share (Wilkinson, 1989).

Community development can be understood as a process of ongoing community social interactions, and as projects or programs that are aimed at implementing change or influencing the community in some way (Wilkinson, 1989). Another distinction can be made between development of community (including for example, capacity building and leadership training), and development in community (including socially or economically focused projects). While both are important from a community development perspective, it is argued that greater precedence should be given to development of community because it relates explicitly to the process of community development, whereas development in community emphasizes locality as a setting for projects or programs (Wilkinson, 1989).

Thus, a development of community perspective focuses on building the capacity of local people for community interaction to collaborate and work together to find solutions to local problems, and to work towards shared objectives that contribute to the well-being of the local community as a whole (Wilkinson, 1989). Such community focused efforts are the essence of community development through their intent to build and improve community.

\section{Top down v. bottom up community development}

National policy efforts to assist rural communities in dealing with the complex effects of demographic, social, economic and institutional change have traditionally focused on 'top down' approaches to community problems through specific government funded projects, where external experts 'solve' community problems.

From a development of community perspective, effective help requires 'bottom up' policy that assists community members to participate actively and collectively in solving their common problems, underpinned by key principles such as self-help, empowerment, networking and equity (Onyx \& Bullen, 1997). 'Bottom up' locally-based approaches have been widely championed (see for example Popham, 1996; Schuftan, 1996; and Mannion, 1996) because such approaches "permit policies to be more socially 
inclusive and help ensure the social stability and cohesion without which economic growth and structural adjustment will be obstructed" (Mannion, 1996, p.1). Too often in the past this has not been the case (Sher, 1986) because development has been done to communities rather than by them. Communities in that situation are vulnerable to and dependent upon external resources and may not readily adapt to change because "dependency depresses adaptive capacity" (Wilkinson 1986, p.8), resulting in, among other things, problems for sustainability.

Contemporary community development strategies in Australia have largely followed those in the US and Europe, emphasising concepts of self help, community empowerment and capacity building. Government policy and funding bodies have encouraged communities to cease relying on government for direction and solutions. Instead, governments have moved to 'empower' communities to seek their own unique solutions, owned by the community and devised 'from the ground up'. However, for CI initiatives, a 'bottom up' approach is limited by the resources available within the community including, for example, financial resources for telecommunications infrastructure and computer hardware, the knowledge, skills and confidence to make effective use of the technology, and the technical knowledge to support and maintain the technology.

Others have recognized the limitations of a 'bottom up' approach and have argued instead for a multilayered and inclusive approach. In such an approach, effective community development results from 'top down' help from government that can be exploited in the context of a 'bottom up' community development process, by communities that have both a strong sense of ownership of their own development process and direction, and the capacity to make full use of it (Lane \& Dorfman, 1997). In this way, complementing well-developed and professional 'top-down' assistance from government with 'bottom-up' community development processes appears an effective means of empowering communities and advancing their wellbeing (Jensen, 1992). While federal and state policies can provide a framework, ultimately, the process of community development must be a local one, an 'inside job', where the community develops as people collaborate and work together to improve their community (Wilkinson, 1986).

For example, the Australian Government's Regional Telecommunications Infrastructure Fund, Networking the Nation (NTN), has directed \$464 million to rural and regional communities for ICT projects since it was first established in 1997. With the intent of achieving community ownership of their own development processes and direction, this funding scheme required rural and regional communities to identify their own ICT related development needs, propose their own ICT solutions, seek financial support through NTN funding to implement the ICT initiative, and then manage their own development process to achieve their intended, and sustainable, outcomes.

When government provides initial financial support in this way for a CI initiative such as NTN, the underlying assumption is that a community has the vision, will and capacity to take 'ownership' of the development process from beginning to end by having a clear perspective on the community's future, undertaking a community needs analysis, identifying possible solutions, implementing and managing the solution, and achieving self-sufficiency and an economically viable outcome.

NTN's commendable intent to achieve community ownership however, masked underlying assumptions that have often proved unrealistic in terms of community capacity and the human, financial, organisational and physical resources required to achieve sustainability. Many of these projects became heavily dependent on volunteer time and support because ongoing awareness raising and education activities to reach all sectors of the community extended well beyond the period of time that the funding allowed. As well, experts and funding did not adequately address the need to develop local leadership or technical support; a focus on the latter could have assisted in amelioration of the lack of locally-based suitably qualified and experienced technical support sufficient to service and maintain equipment and infrastructure. Increased costs, inconvenience and offline time as hardware is sent elsewhere for repair can seriously undermine the effectiveness of CI projects. And now, with the NTN funding scheme ending, communities need to seek alternative financing solutions for the ongoing viability of their CI initiatives (DCITA, 2003). This challenge is even greater for rural and remote communities with fewer opportunities for alternative sources of funding. The often flawed underlying assumption is that communities have both access to alternative funding sources and the capacity to seek out and negotiate such funding. 
In reality, many communities do not have such capacity and their NTN sponsored initiatives have ceased operating as government funding has been withdrawn. In this context, capacity building clearly needs to be a key element of CI initiatives.

\section{Capacity building}

Much of the basis for achieving more sustainable bottom-up community development lies in building community capacity (Cavaye, 1999; Labonte, 1999). However, community capacity building rarely receives the attention and investment it warrants, particularly when lack of capacity building can result in failed or unsustainable projects (Blackwell \& Colmenar, 1999). Capacity building empowers and motivates local people to contribute to their maximum potential for the development of their community through an openness and preparedness for change (Gannon, 1998). Local participation and development are fostered through strengthening the knowledge, skills and attitudes of community members so that they can create and adapt local institutions toward sustaining their area's development, and providing opportunities for meaningful involvement in the development process (Mannion, 1996). More specifically, community capacity consists of building the networks, organisations, attitudes, leadership and skills that allow communities to manage change and sustain community-led development (Cavaye, 1999). Thus, community capacity building requires a two-pronged approach: developing the capacity of individuals through soft technologies and strengthening community social infrastructure (Milio, 1996).

Developing individual capacity requires access to a range of 'soft technologies', i.e. those "technologies" that enable individuals to learn about and use hard technologies (such as ICTs) or to manage CI initiatives (such as awareness raising, education and training, and building leadership). These can include:

- Formal programs and informal activities that increase awareness of the potential and benefits of ICTs.

- Formal and informal education and training programs that equip community members with the skills and knowledge required to become competent users of ICTs.

- Building leadership across community groups and organisations where individuals become the 'local champions' encouraging others to engage with ICTs, or managing the CI initiative.

- Building technical expertise for supporting and maintaining information and communication technologies.

Strengthening social infrastructure enables the interaction and building of interrelationships as community members engage with one another and with diverse local organisations and institutions, networks, community resources and services, and community groups. In the context of CI initiatives, this includes the formal and informal education and training organisations as well as social networks that facilitate engagement with and increased use of ICTs.

The challenge to government and other external agents or funding bodies, therefore, is to acknowledge that access to hard infrastructure alone will not maximise diffusion and uptake of ICTs, and to adequately resource community capacity building strategies. This means finding ways to support and ensure the sustainability of education and training initiatives at least until the majority of community members have acquired skills, not just the innovators and early adopters. Strategies to address inadequacies in community capacity or capitalise on and strengthen existing social infrastructure are also essential to the development of sustainable CI initiatives.

A further challenge for government is how to enable processes of capacity building, consultation and community ownership without creating unreasonable pressures on the time, personal energy, finances and skills of rural community members. Many communities do not have the spare capacity or access to the high level skills (including expertise in community conflict resolution, fund raising, marketing, and community consultation and mobilisation) required to achieve sustained outcomes for CI initiatives.

Community development projects that are devolved too early to the community or under-resourced (both financially and in terms of working with local social infrastructure), or that inflate community expectations and then leave the community to fend for itself are unlikely to enjoy sustained success. This is particularly the case for $\mathrm{CI}$ initiatives that require ongoing, sustained awareness-raising and education components to ensure widespread accessibility to all sectors of the community. Community empowerment 
and capacity-building models of CI implementation can potentially have substantial benefits for communities if they are implemented, with adequate resource availability and careful consideration of the long term impacts, both positive and negative, that community development initiatives may have on the community.

\section{Learnings from community development and capacity building}

In terms of CI initiatives, community development and capacity building highlight the importance of:

- Identifying strategies for capitalizing on professional support, expertise and funding from external agencies and government that can be accessed by communities as a foundation for building their 'own' CI initiatives.

- Working within the norms and beliefs of the local social system, by ensuring that local community members drive and 'own' $\mathrm{CI}$ initiatives. This requires active involvement in all stages of the project, including determining community objectives, planning and developing appropriate strategies for implementation and for ongoing review and evaluation of the initiatives' outcomes.

- Analysing existing levels of awareness, ICT skills, leadership and social infrastructure in the community.

- Ensuring that planning for CI initiatives includes adequate resourcing and strategies to not only provide access to the hard technologies but, as well, to address soft technology education and training needs, and to strengthen social infrastructure.

- Identifying ways of tapping into, and building on, existing social infrastructure to facilitate the participation of all community members in local networks by ensuring programs are accessible to a diversity of community members and providing ongoing support for learners.

- Creating opportunities for existing community leaders and emergent leaders to facilitate other community members' engagement with ICTs.

Effective community development involves the social institutions and networks present in the community to influence attitudes to change, and to provide opportunities for meaningful involvement. As individuals become usefully involved and work together on deliberate, community focused efforts, new networks and relationships are formed, and existing networks and relationships strengthened, contributing to the growth of community social capital (Bridger \& Luloff, 1999).

The paper now turns to a discussion of social capital and highlights why building social capital matters for the sustainability of CI initiatives.

\section{Social Capital}

Social capital is another often contested concept, with varying definitions (see for example Bourdieu, 1985; Coleman, 1988; Putnam, 1993). For this paper, "social capital" is understood as an outcome of interaction and participation in networks, rather than as a process. As individuals come together to work for their community, valuable relationships can be developed across the diverse interest lines that exist within communities. These relationships contribute to the growth of social capital as they create new information sources, reciprocal obligations and expectations, increased trust and shared norms (Bridger \& Luloff, 1999).

It is not the purpose of this paper to provide a critical analysis of the many definitions of social capital, or an extensive review of the social capital literature. Rather the paper seeks to highlight those aspects of social capital that contribute to a framework for understanding the complexities associated with implementing and sustaining CI initiatives. A social capital perspective has proved particularly useful in understanding these complexities (see Simpson et al., 2001). This paper draws on a definition of social capital that refers to the valuable but intangible social features of community life - such as trust and cooperation between individuals and within groups, actions and behaviour expected from community members, networks of interaction between community members, and actions taken by community members 
for reasons other than financial motives or legal obligations - that can potentially contribute to the wellbeing of that community (Longo, 1999).

\section{Networks and ties}

Social capital cannot be generated by individuals acting in isolation, but instead depends on a propensity for sociability and a capacity to form new associations and networks (Onyx \& Bullen, 1997). Rural communities typically have a diversity of networks that link groups with different characteristics (Flora et al., 1997). Such social connectedness can vary from intimate ties with people like oneself (bonding social capital), through to outward-looking, diverse, often instrumental relationships with people unlike oneself (bridging social capital) (Putnam, 2000). The critical issue is whether individuals and, by extension, their communities, maintain a balance between the two extremes.

Strong intimate ties are important contributors to social capital because of the trust and reciprocity they promote between people who know one another well. However, only mixing with known associates can limit exposure to new ideas. Weaker ties link community members to those not known quite so well (Granovetter, 1982). These ties provide access to skills, expertise and resources not available in their 'inner circle' and build social capital in a different way. They facilitate opportunities, broaden perspectives, and stimulate new ideas and new knowledge, providing opportunities for leadership and pro-activity.

The mix of ties, therefore, significantly impacts on social organisation in communities, and the cultural characteristics, such as the acceptance of diverse leadership, that stimulate or suppress change. If the balance between bonding and bridging social capital is 'right', a community can build levels of trust and commitment that enable the skills and confidence of a wide range of community members (rather than only those historically in positions of power) to be utilised and developed. This provides a fertile environment for the emergence of leaders of different styles, with varying strengths and skills, who can stimulate proactive community action, and further develop bridging social capital. Such leadership often emerges from an individual's or a small group's passion and commitment to a particular project, and their resulting role as a local 'champion'. Thus, communities that are high in social capital have diversified leadership representative of the age, gender and cultural composition of the community (Center for Community Enterprise, 2000).

Social capital also helps to explain why some communities remain viable and others do not (Wall, Ferrazzi \& Schryer, 1998). Putnam (1993) argues that social capital in communities tends to be polarised by virtuous and vicious cycles moving communities to opposite ends of a continuum. A self-reinforcing virtuous cycle sustains 'competent' communities with high social capital, while a vicious cycle traps "uncivic" (or dysfunctional) communities into diminishing social capital. In "un-civic" communities, people are not empowered to participate, only weak social networks are developed and individuals have limited opportunities to develop trust. Poor awareness of community activities leads to a lack of concern and consequently poor involvement and little cooperation.

On the other hand, cooperating and participating in community activities such as $\mathrm{CI}$ initiatives extends social networks, develops trust and confidence, and creates greater community awareness, leading to greater social capital and more vital, strategically managed communities (Cavaye, 1997). The unique potential of $\mathrm{CI}$ initiatives is the richness of interactive, informal communication, horizontal and vertical, which the technology makes possible, and the greater diversity and breadth of networks and ties that can emerge from increased participation and interactivity in the community. Social capital can thus both contribute to and result from community development processes (Onyx \& Bullen, 1997), with potential for the benefits to be magnified through the interactivity provided by $\mathrm{CI}$ initiatives.

\section{Learning from social capital}

In terms of CI initiatives, social capital highlights the importance of:

- Building community capacity in awareness of the potential of the $\mathrm{CI}$ initiative so that there is a shared understanding of the extent to which the initiative can contribute to the community's aspirations, values and needs and the future well being of the community. 
- Exploiting the capability of the $\mathrm{CI}$ initiative to build new forms of social infrastructure through local and external networks across diverse groups in the community, exposing community members to a broader range of ideas and facilitating emergent leadership and pro-activity.

- Encouraging and enabling local community ownership of the CI initiative, underpinned by adequately resourcing the initiative in terms of physical infrastructure, soft technologies and social infrastructure so pre-existing levels of social capital are not diminished by undue demands on the community, such as volunteering.

- Understanding the importance of appropriate environments and sociability to the implementation of CI initiatives for fostering social inclusion, community interaction, building community cohesiveness and strengthening local networks, particularly for marginalised groups in the community.

The paper now turns to a closer examination of the links between sustainability and social capital to further explain why social capital matters to the sustainability of CI initiatives.

\section{Sustainability}

There is considerable debate regarding the role of development in ensuring the sustainability of rural communities in the face of current trends including environmental degradation, population decline and the reduction of infrastructure and services in rural communities. For example, Cernea (1993) challenges the 'econo-mythical invocation' of those who usually define sustainability in economic and ecological terms, and who often claim that providing a sound economic base ensures that everything will fall into place. Instead, Cernea argues that the social components of sustainability are equally important as for example in 'putting people first', thereby improving social organization, increasing social capital and recognizing the centrality of community members and community organizations to the sustainability of communities and their CI initiatives (Cernea, 1993). Similarly, the World Bank (1998) highlighted the growing body of evidence that the size and density of social networks and institutions and the nature of interpersonal interactions are significant determinants of the sustainability of development initiatives.

On the other hand, sustainable communities are also described as those where local community action is significantly shaped by interaction with global trends and agencies, but is balanced by action at the local community level to not only protect and enhance their immediate environment but also to promote more humane local societies (Bridger \& Luloff, 1999). Sustainable communities thus are underpinned by outcomes of interactions within the local community, between community members and groups, and with external agencies. Such a view stresses the interactions and linkages that lead to collective actions and political relationships essential for the development of more sustainable communities, and argues that sustainable community developments need "an explicit policy emphasis on strategies to build the community field and generate social capital" (Bridger \& Luloff, 1999, p.15). Fostering sustainable community development is thus dependent on understanding how social capital is created, and on an awareness of how social capital can underpin sustainable CI initiatives in rural communities. This requires an appreciation of the way social capital (in terms of trust, active relationships, participation and collaboration) is utilized to produce real changes in the social and economic life of the community. A rationale for a framework that brings together elements of diffusion of innovation, community development and capacity building, and social capital to provide a foundation for the effective implementation of sustainable CI initiatives is now provided.

\section{Towards a framework for successful CI initiatives}

CI implementation needs to be facilitated by a prepared technical environment, but equally the target community needs to be ready to engage with the technology (Easdown, 1997; Gillard et al., 1996; The Rural Women and ICTs Research Team, 1999). A community's receptiveness to a CI initiative is influenced by the extent to which the initiative matches the community's aspirations, values and needs, or is perceived as contributing to the future well being of the community. Community aspirations, values and 
needs, and a shared sense of the future well-being of the community are aspects of social capital. The extent to which social capital exists in a community is therefore a critical factor in the community's receptiveness to $\mathrm{CI}$ initiatives and its acceptance of the technology, and consequently the likelihood of the CI initiative to succeed and be sustained (Mannion, 1996).

Effective planning for CI initiatives needs to assess and build on the level of social capital present in a community, and to incorporate strategies directed towards building community capacity from two perspectives. First, drawing on diffusion of innovations and community development, the two components of 'soft technology' and 'social infrastructure' assist in understanding how CI initiatives are diffused through capacity building. These components interact with one another, and with existing levels of social capital within the community, to encourage widespread uptake of the initiative by building the skills and confidence of individuals and by strengthening community networks and organisations.

Second, by understanding the construct 'social capital', CI initiatives can foster the type of capacity that is desirable or the elements present in (and necessary to) 'resilient' communities. Elements such as proactivity, a strong sense of community, and a shared vision for the future underpin a community's willingness to ensure sustainability of CI initiatives. Once accepted, a CI initiative has the potential to increase the levels of social capital in the community, by providing additional powerful forms of social infrastructure as for example in the use of the technology to expand access to both internal and external networks.

Recognition of these components provided the basis for the development of a conceptual framework (see Figure 1 below) that emphasises the interplay between physical infrastructure, soft technologies, social infrastructure and social capital as critical elements in the foundation for effective implementation and sustainability of CI initiatives. An adequate framework that encompasses the complexity of CI initiatives therefore needs to incorporate the following key components:

- Physical infrastructure and its location - the hard technology (e.g. telecommunications infrastructure) and the physical equipment (such as telephones and computers) and its location in the community. Local access should take account of the local social norms that govern how various community members will interact with the technology in specific locations. This requires a diversity of access points to cater for differing needs, or ensuring that the access point has the flexibility to be used in diverse ways to meet differing needs.

- Soft technology - the formal and informal activities including awareness raising, education and training, building leadership and providing opportunities for leadership to emerge, and other capacity building activities that develop the skills and knowledge required by community members to maximise the use of ICT and to manage the CI initiative.

- Social infrastructure - the structural arrangements including community organisations and institutions, networks, volunteerism, and community services and resources that enable individuals and groups to interact with one another.

- Social capital - the intangible social features that are outcomes from interaction and participation in local and external networks such as a strong sense of community; shared values, norms and visions for the community; trust, reciprocity and cooperation; formal and informal leadership; and pro-activity. 


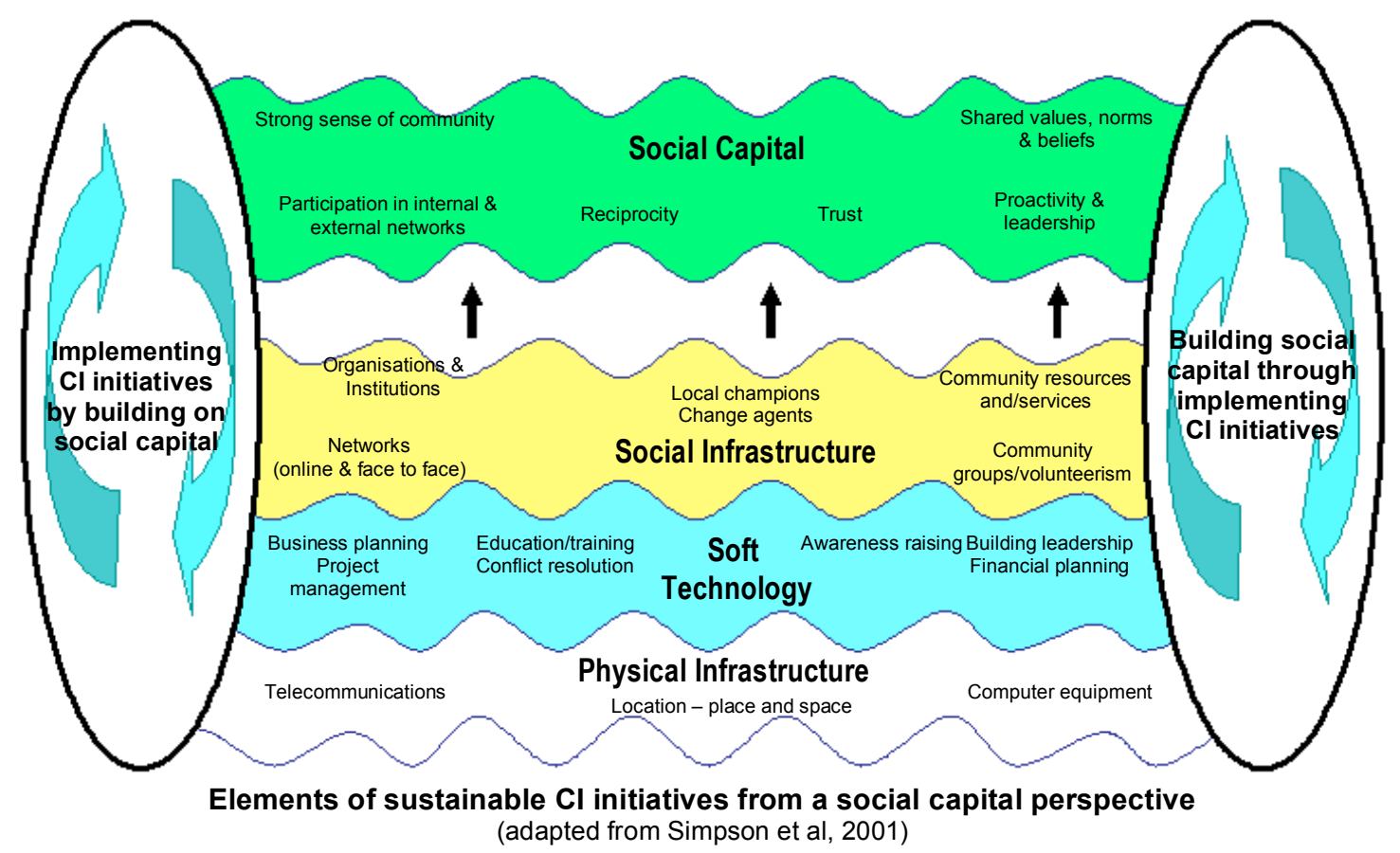

Figure 1

These elements are interwoven, and interact so that social capital both emerges from and feeds back into the community. Communities that have high levels of social capital with an openness to change will engage in ongoing consideration of the opportunities to be derived from the CI initiative. The framework also acknowledges the cyclic nature and interplay between the various components, essential to successful $\mathrm{CI}$ initiatives where community needs and outcomes of CI initiatives are constantly being evaluated, reevaluated and realigned.

The need for a strong sense of community and high levels of social capital as essential to sustainable CI initiatives are also emphasised in the framework. Equally, CI initiatives that foster widespread participation and social inclusion and enable greater interaction in local and external networks will contribute to a stronger sense of community and increased social capital, thereby ensuring greater potential for sustainability.

\section{Conclusion}

$\mathrm{CI}$ initiatives are a significant component of the response required of rural communities to the growing importance of ICTs in daily life, particularly to minimise the impact of lack of access to ICTs for people subject to financial, structural and cultural constraints. Understanding the role of social capital in the success of CI initiatives as community development actitivies and widespread adoption of ICTs can enhance the likelihood of the sustainability of the CI initiative, thereby increasing the benefits that the community may derive. A framework has been proposed that brings together key factors from theories of diffusion of innovation, community development and capacity building, and social capital for consideration when implementing $\mathrm{CI}$ initiatives.

First, diffusion theory highlights the need for long term ICT access, accompanied by adequate attention to how and where the CI initiative is located so that the environment can be adapted to meet the diverse needs of individuals and groups in the community, and to allow community members the opportunity to trial and explore the relevance of the technology. 
Second, community development and capacity building emphasise the need for the CI initiative to include appropriate soft technologies, such as awareness raising, education and training, and building local, diverse leadership to support the uptake of the technology. These activities need to capitalize on the community's social infrastructure, working with the widest variety of community groups and organisations to ensure that all those who stand to benefit from the CI initiative have the opportunity to become involved, both as a means of encouraging participation and as a source of support while skill and confidence is developed. CI initiatives themselves have the potential to become part of the social infrastructure of the community, providing fresh opportunities for bringing together diverse members of the community around the common purpose of engaging with ICT.

Third, attention to the social capital implications of $\mathrm{CI}$ initiatives can enhance their contribution to the local community. By providing new forms of community organisation, interaction and interrelationships, $\mathrm{CI}$ initiatives can facilitate increased participation by a broad diversity of community members. The unique potential of CI initiatives to provide a new richness to communication - horizontal and vertical, internal and external to the community - increases the breadth and diversity of ties through increased participation, while exposing the community to a greater range of information, ideas and future options. Increased participation in turn can facilitate trust and cooperation, and reciprocity. Strengthening community bonds creates a stronger sense of community and a shared sense of future, and builds social capital. Resilient communities with high levels of social capital will be more proactive in seeking ways to sustain the CI initiative.

Capacity-building models are increasingly guiding government policy and action and can have considerable benefit for communities if they are realistically implemented with adequate resourcing and careful consideration of the long-term impacts (both positive and negative). When resources are made available that build local ownership of the CI initiative and support the mobilisation of local effort, communities can be empowered to find and act upon their own sustainable solutions.

Thus, the sustainability of $\mathrm{CI}$ initiatives is largely dependent not only on the extent to which the project addresses community needs and issues, but also on the processes used to achieve this. A 'top-down' government initiative to supply limited term funding and staff to meet a perceived community need for technological access may have short term benefits, but is unlikely to strongly influence the growth of community capacity, or have positive long term effects on the social capital of that community unless the social aspects of the local environment are taken into account.

Projects must be designed in such a way that they are supported by soft technologies that help to build local capacity and leadership, encourage community ownership and strengthen local social infrastructure and networks, and therefore build social capital. If these factors are neglected, the impacts of a CI initiative can be limited and short-lived. The negative impacts resulting from the failure of a community-focused CI initiative may spread so far as to have a flow-on detrimental effect on the community's social capital, thereby undermining not just the sustainability of the CI initiative, but the sustainability and resilience of the community as a whole.

\section{References}

Albrechtsen, H. (1998). The telecottages in the Nordic countries. Telecommunications Journal, 55(5), 307315.

Bikson, T. \& Panis, C. (1995). Computers and connectivity: current trends. In Universal Access to E-mail: Feasibility and Societal Implications, eds R. H. Anderson, T. K. Bikson, S. A. Law \& B. Mitchell. Santa Monica: RAND Corporation, viewed 26 March 2003, http://www.rand.org/publications/MR/MR650/

Blackwell, A. \& Colmenar, R. (1999). Transforming policy through local wisdom. Futures, 31(5).

Bourdieu, P. (1985). The forms of capital, in J.G. Richardson (ed.), Handbook of theory and research for the sociology of education. New York: Greenwood Press. 
Bridger, J. C., \& Luloff, A. E. (1999). Sustainable Community Development: An Interactional Perspective. Available: http://www.cas.nercrd.psu.edu/Community/Legacy/bridger community.html

Cavaye, D.J. (1999). The Role of Government in Community Capacity Building. Brisbane: Department of Primary Industries.

Cernea, M. (1993, December). The Sociologists Approach to Sustainable Development. Finance and Development.

Center for Community Enterprise (2000). The Community Resilience Manual: A Resource for Rural Recovery and Renewal. Center for Community Enterprise, Port Alberni, Canada, viewed 24 March 2003, http://www.cedworks.com/cgibin/loadpage.cgi?id+fs_crpregistratn.html

Charlton, C., Gittings, C., Leng, P., Little, J., \& Neilson, I. (1998). Diffusion of Technology Innovations: Bringing businesses on to the Internet. In T. J. Larsen \& E. McGuire (Eds.), Information Systems Innovation and Diffusion: Issues and Directions. Hershey, USA: Idea Group Publishing.

Coleman, J.S. (1988). Social capital in the creation of human capital. American Journal of Sociology, 94.

Dabinett, G. (2000). Regenerating Communities in the UK: Getting Plugged Into the Information Society? Community Development Journal, 35(2), 157-166.

Daws, L, Seinen, A., Simpson, L. \& Wood, L. (2001). Creating Rural Connections: Book 2: Education and Training. Brisbane: The Communication Centre, QUT.

Department of Communications, Information Technology and the Arts (DCITA) (2003). Maintaining the Viability of Online Access Centres in Regional, Rural and Remote Australia, discussion paper, [Available on-line: www.dcita.gov.au/Article/0,0_2-1_1-2_5-4_117050,50.html, (accessed 24 November 20003)].

Easdown, W. (1997). The Role of the Internet in Rural Communities (Occasional Paper). Gatton: University of Queensland, Gatton College.

Falk, I. (1999). Situated Leadership: A New Community Leadership Model. Launceston, Tasmania: Centre for Research and Learning in Regional Australia.

Fischer, C.S. (1994). America Calling: The Social History of the Telephone to 1940. Berkeley: University of California Press.

Flora, J.L., Sharp, J. \& Flora, C. (1997). Entrepreneurial Social Infrastructure and Locally Initiated Economic Development in the Nonmetropolitan United States. The Sociological Quarterly, 38, 623645 .

Fukuyama, Francis. (1995). Trust: The Social Virtues and the Creation of Prosperity. New York: The Free Press.

Gannon, A. (1998). Mastering Change: a New Paradigm in Building Positive Futures for Rural Communities. Paper presented at the Positive Rural Futures Conference, Biloela, Queensland, Australia, May 28-30.

Gillard, P., Wale, K., \& Bow, A. (1996). Re-engineering telecommunications for the way people want to live: social research in the design of new technologies. Prometheus, 14(1), 80-89.

Goodman, R.M. (1998). Identifying and defining the dimensions of community capacity to provide a basis for measurement. Health Education and Behaviour, 25(3), 258-278.

Granovetter, M. (1982). The strength of weak ties. The American Journal of Sociology, 78(6), 1360-1380.

Grunwald, T. (1997). Making the Net Work: Online Strategies for Community Based Organisations. London: UKCO.

Gurstein, M. (1999). Flexible Networking, Information and Communications Technology and Local Economic Development. First Monday, 4(2). 
Gurstein, M. (2001). Community Informatics, Community Networks and Strategies for Flexible Networking in L. Keeble and B. Loader (eds) Community Informatics: Shaping Computer-mediated Social Relations, Routledge, London

Haberkorn, G., Hugo, G., Fisher, M., \& Aylward, R. (2000). Country Matters: Social Atlas of Rural and Regional Australia. Kingston, ACT: Bureau of Rural Sciences, Department of Agriculture, Fisheries and Forestry.

Hellman, H. (1996). A Toy for the Boys Only? Reconsidering Gender Effects of Video Technology. European Journal of Communication, 11(1), 5-32.

Horner, D. \& Reeve, I. (1991). Telecottages: the potential for rural Australia. Armidale: The Rural Development Centre.

Hunter, A. (1999). Opportunity through CI for regional Australia. Paper presented at the Regional Australia Summit. Canberra: Department of Transport and Regional Services.

Innovate Australia (1995). Innovate Australia - Information and Communications Services and Technologies, viewed 25 March 2003, http://www.dist.gov.au/events/innovate/

Jensen, R.C. (1992). Regional development and the Central Queensland Region. Central Queensland Journal of Regional Development, 5-10.

Kautz, K. (1999). Editorial: Special Issue on Diffusion, transfer and adoption of information technology innovations. Information Technology \& People, 12(1), i-x.

Kautz, K., \& Larsen, E. A. (2000). Diffusion theory and practice: Disseminating quality management and software process improvement innovations. Information Technology \& People, 13(1), 11-26.

Kiesler, S. (1986). Thinking Ahead: the hidden messages in computer networks. Harvard Business Review, January-February, 46-60.

Kling, R. (2000). Learning about Information Technologies and Social Change: The Contribution of Social Informatics. The Information Society, 16, 217-232.

Korsching, P., Hipple, P. C., \& Abbott, E. A. (2000). Rural America and the Information and Communications Revolution. In P. Korsching, P. C. Hipple \& E. A. Abbott (Eds.), Having all the Right Connections: Telecommunications and Rural Viability. Westport, Connecticut: Praeger.

Labonte, R. (1999). Social Capital and Community Development: Practitioner Emptor. Australia and New Zealand Journal of Public Health, 23(4), 430-433.

Lane, B. \& Dorfman, D. (1997). Strengthening Community Networks: The Basis for Sustainable Community Renewal. Oregon: North West Regional Educational Laboratory, viewed 25 March 2003, http://www.nwrel.org/ruraled/Strengthening.html

Longo, J. (1999). Multiple Meanings and a Myriad of Terms in the Space between the Market and the State, Working Paper. Victoria, Canada: Centre for Public Sector Studies.

Mannion, J. (1996). Partnership, participation and capacity building: rural development based on local bottom-up strategies. Leader Magazine, 12 (Oct.). Available at http://www.rural-europe.aeidl.be/ruralen/biblio/defis/art02.htm

Milio, N. (1996). Engines of Empowerment. Ann Arbor: Health Administration Press.

National Office for the Information Economy (2000), The Digital Divide. Canberra: National Office for the Information Economy, viewed 25 March 2003.

http://www.noie.gov.au/projects/access/Connecting_Communities/Digitaldivide.htm

Smith, G. (1996). Community-arianism: Community and Communitarianism: Concepts and Contexts. UK Communities Online, http:///www.communities.org.uk. [2001, 7 March]

Oldenburg, B., Hardcastle, D. M., \& Kok, G. (1997). Diffusion of innovations. In K. Glanz, F. M. Lewis, \& B. K. Rimer (Eds.), Health Behaviour and Health Education. San Francisco: Jossey-Bass Publishers. 
O'Neil, D. (2002). Assessing community informatics: a review of methodological approaches for evaluating community networks and community technology centres. Internet Research: Electronic Networking Applications and Policy, 12(1), 76-102.

Onyx, J. \& Bullen, P. (1997). Measuring Social Capital in Five Communities in NSW: A Practitioner's Guide, Working Paper 41. Coogee, Australia: Management Alternatives Pty. Ltd.

Onyx, J., \& Bullen, P. (2000). Sources of social capital. In I. Winter (Ed.) Social Capital and Public Policy in Australia. Melbourne: Australian Institute of Family Studies.

Popham, J. (1996). Empowerment through community enterprise. Local Government Policy Making. 23(2), 26-30.

Putnam, R. D. (1993). The prosperous community: Social capital and public life. The American Prospect Inc. 13, (Spring).Available at epn.org/prospect/13/13putn.html

Putnam, Robert D. (2000). Bowling Alone. New York: Simon and Schuster.

Queensland Department of Communication, Information, Local Government and Planning (1999), Queensland Communication and Information Strategic Plan 1999-2004. Brisbane.

Rheingold, H. (1993). The Virtual Community: Homesteading on the Electronic Frontier. Reading, MA: Addison Wesley.

Rogers, E. M. (1995). Diffusion of Innovations (4th ed.). New York: The Free Press.

Rural Women and ICTs Research Team (1999). The New Pioneers: Women in Rural Queensland Collaboratively Exploring the Potential of Communication and Information Technologies for Personal, Business and Community Development. Brisbane: The Communication Centre, QUT.

Schuftan, C. (1996). The community development dilemma: what is really empowering. Community Development Journal, 31(3), 260-264.

Sher, J.P. (1986). Rural development worthy of the name. In US Congress, Joint Economic Committee, New dimensions in rural policy. Washington, DC: Government Printing Office.

Sher, J.P., \& Sher, K.R. (1994). Beyond the Conventional Wisdom: Rural Development as if Australia's Rural People and Communities Really Mattered. Journal of Research in Rural Education, 10(1), 2-43.

Simpson, L., Wood, L., Daws, L. \& Seinen, A. (2001). Creating Rural Connections: Book 1: Project Overview. Brisbane: The Communication Centre, QUT.

Simpson, L. (1998). Use of and Expected Benefits from the Provision of Local Internet Access, Interim Report Volume 1. Brisbane: The Communication Centre, QUT.

Smith, G. (1996). Community-arianism: Community and Communitarianism: Concepts and Contexts. UK Communities Online, http://www.communities.org.uk [2001, 7 March].

Tornatzky, L \& Fleischer, M. (1990). The Process of Technological Innovation. New York: Lexington Books.

US Congress Office of Technology Assessment (1991). Rural America at the Crossroads: Networking for the Future. Washington, DC: US Government Printing Office.

Valente, T. W., \& Davis, R. L. (1999). Accelerating the diffusion of innovations using opinion leaders. Annals of the American Academy of Political and Social Science, 566, 55-67.

Wall, E., Ferrazzi, G. \& Schryer, F. (1998). Getting the goods on social capital. Rural Sociology, 63(2), $300-323$.

Warschauer, M. (2003, August). Demystifying the Digital Divide. Scientific American.

Wilding, D. (2001). Bridging the digital divide. Data, June, p.10.

Wilkinson, K. (1986). The small town community: its character and survival. Third Biennial GITAP Interdisciplinary Conference. Grand Forks, North Dakota. 
Wilkinson, K. (1989). The future of community development. In J. Christenson \& J. Robinson (Eds.), Community Development in Perspective. Ames: Iowa State University Press.

Woolcock, M. (1998). Social capital and economic development: Towards a theoretical synthesis and policy framework. Theory and Society, 27, 151-208.

Woolcock, M. (2001). The place of social capital in understanding social and economic outcomes. isuma: Canadian Journal of Policy Research, Spring, 11-17. 